\title{
Difluorobenzothiadiazole based two-dimensional conjugated polymers with triphenylamine substituted moieties as pendants for bulk heterojunction solar cells
}

\author{
W. H. Lee ${ }^{1}$, B. T. Liu $^{2}$, R. H. Lee ${ }^{1 *}$ \\ ${ }^{1}$ Department of Chemical Engineering, National Chung Hsing University, 402 Taichung, Taiwan \\ ${ }^{2}$ Department of Chemical and Materials Engineering, National Yunlin University of Science \& Technology, 640 Yunlin, \\ Taiwan, R.O.C.
}

Received 5 April 2017; accepted in revised form 24 June 2017

\begin{abstract}
Three donor/acceptor (D/A)-type two-dimensional polythiophenes (PTs; PBTFA13, PBTFA12, PBTFA11) featuring difluorobenzothiadiazole (DFBT) derivatives as the conjugated (acceptor) units in the polymer backbone and tertbutyl-substituted triphenylamine ( $t$ TPA)-containing moieties as (donor) pendants have been synthesized and characterized. These PTs exhibited good thermal stabilities, broad absorption spectra, and narrow optical band gaps. The cutoff wavelength of the UV-Vis absorption band was red-shifted upon increasing the content of the DFBT units in the PTs. Bulk heterojunction solar cells having an active layer comprising blends of the PTs and fullerene derivatives $[6,6]$ phenyl- $\mathrm{C}_{61 / 71}$-butyric acid methyl ester $\left(\mathrm{PC}_{61} \mathrm{BM} / \mathrm{PC}_{71} \mathrm{BM}\right)$ were fabricated; their photovoltaic performance was strongly dependent on the content of the DFBT derivative in the PT. Incorporating a suitable content of the DFBT derivative in the polymer backbone enhanced the solar absorption ability and conjugation length of the PTs. The photovoltaic properties of the PBTFA13-based solar cells were superior to those of the PBTFA11- and PBTFA12-based solar cells.
\end{abstract}

Keywords: polymer synthesis, difluorobenzothiadiazole, polythiophene derivative, and bulk heterojunction solar cells

\section{Introduction}

Conjugated polymers with electron donor/acceptor $(\mathrm{D} / \mathrm{A})$ units in the polymer backbone have attracted much attention for their applications in optoelectronic devices, including polymer solar cells (PSCs), organic thin film transistors (OTFTs), and polymer light emitting displays (PLEDs) [1-7]. Major advances in the solar energy conversion efficiencies of PSCs have been accomplished by replacing the double-layer cell with a bulk-heterojunction (BHJ) based on a conjugated polymer/fullerene derivative blend as the photoactive layer [8-10]. The bipolar characteristics of D/A-type conjugated polymers, containing both electron- and hole-transporting moieties, can result in lower-energy band gaps and higher charge mobilities for the photoactive layers, thereby enhancing the PV efficiencies of PSCs [11-15]. Polythiophene (PT) derivatives bearing electron-donating and -withdrawing pendant groups, so-called two-dimensional (2-D) low band gap conjugated polymers, have been proposed by several groups for PSC applications [16-25]. The introduction of conjugated moieties as pendant units that absorb broadly in the UV and visible regions can, therefore, lead to the greater harvesting of solar light. Moreover, the conjugated pendant moieties can enhance the charge mobilities of the polymers.

The incorporation of electron-deficient moieties within the polymer backbone and the appending of electron-donating units would, ideally, promote charge 
balance and efficient conjugation within the extended conjugated framework of the polymer [26-28]. Triphenylamine (TPA) derivatives are among the most popular electron-donor groups because of their good electron-donating and hole-transporting performance, and good solubility in organic solvents [29, 30]. Fan et al. [30] reported two benzodithiophene-based 2-D polymers featuring extended conjugated thienyltriphenylamine substituents; polymers presenting these extended TPA-based conjugated pendants exhibited good thermal, photophysical, and photovoltaic performance. In addition, benzothiadiazole (BT) derivatives are widely used as acceptor units because of their strong electron-withdrawing properties, intense light absorption, and good photochemical stability $[31,32]$. Many BT-based conjugated polymers providing good PV performance have been synthesized through the copolymerization of BT units with various electron-donating groups (e.g., benzodithiophene, dithienosilole, $4 H$-cyclopenta[2,1$\left.b ; 3,4-b^{\prime}\right]$ dithiophene) [33-35]. Furthermore, incorporating fluorine atoms at the 5- and 6-positions of the BT unit can lower the energy levels of the lowest unoccupied molecular orbital (LUMO) and highest occupied molecular orbital (HOMO) of the resulting conjugated polymers, resulting in PSCs displaying higher open-circuit voltages; higher hole mobility is also obtained because of stronger intermolecular interactions among the polymer chains [30, 36-38]. The PV performance of difluorobenzothiadiazole (DFBT)-based polymers is usually superior to that of BT-based polymers [39-41]. Nevertheless, the introduction of DFBT units into polymer backbones usually results in conjugated polymers having poor solubility $[38,42]$.

Recently, we synthesized a series of PTs presenting conjugated TPA-containing moieties as side chains [22]. The incorporation of bulky pendant units in a PT twists the main chain out of planar $\pi$-conjugation, thereby decreasing the effective conjugation length of the polymer backbone [43-47]. As a result, these PTs have higher band gap energies and are less capable of harvesting solar light [17]. Therefore, precise control over the molar ratio of the electron-donating and -withdrawing units in the polymer chain is necessary to optimize the solubility, film quality, and optical and PV performance of resulting devices. To test this concept, in this study we synthesized three 2-D PTs (PBTFA13, PBTFA12, PBTFA11) featuring DFBT derivatives as the conjugated units in the polymer backbone with tert-butyl-substituted triphenylamine ( $t$ TPA)-containing moieties as pendant units. UV-Vis absorption spectroscopy and cyclic voltammetry $(\mathrm{CV})$ revealed the effect of the DFBT content on the photophysical and electrochemical properties of the polymers. We also employed atomic force microscopy (AFM) and transmission electron microscopy (TEM) to study the morphologies of thin films prepared from the PT/ $\mathrm{PC}_{61} \mathrm{BM}$ blends. We then fabricated PSCs having a conventional structure [indium tin oxide (ITO)-coated glass/hole-transporting medium (HTM)/photoactive layer/Ca $(20 \mathrm{~nm}) / \mathrm{Al}(100 \mathrm{~nm})]$, spin-coating a blend of each $\mathrm{PT}$ with $\mathrm{PC}_{61} \mathrm{BM}$ or $\mathrm{PC}_{71} \mathrm{BM}$ to form a composite film-type photoactive layer on the HTM layer deposited on ITO-coated glass. From studies of the PV performance of these PSCs, herein we discuss the influence of the DFBT content of our PTs on the PSC performance.

\section{Experimental details \\ 2.1. Chemicals}

Tris(dibenzylideneacetone)dipalladium $(0)\left[\mathrm{Pd}_{2}(\mathrm{dba})_{3}\right]$, tri (o-tolyl $)$ phosphine $\left[\mathrm{P}(o \text {-tolyl })_{3}\right]$, and other reagents and chemicals were purchased from Aldrich ( $\mathrm{St}$ Louis, MO, USA), Alfa (New Jersey, USA), Acros (Geel, Belgium), and TCI Chemical (Tokyo, Japan), and used as received. $o$-Dichlorobenzene $(o$-DCB) was freshly distilled over appropriate drying agents prior to use as a solvent, and was purged with $\mathrm{N}_{2}$. 2,5-Bis(trimethylstannyl)thiophene (1) and (E)-4- \{5[2-(2,5-dibromothien-3-yl)vinyl]thien-2-yl $\}-N, N$ $\left[\left(4,4^{\prime}\right)\right.$-di-tert-butyl)diphenyl]aniline (2) were synthesized according to procedures reported in the literature [29, 48, 49]. 4,7-Bis(5-bromothien-2-yl)5,6-difluorobenzo[ $c][1,2,5]$ thiadiazole (3) was purchased from SunaTech and used as received. The synthesis of the PTs PBTFA11, PBTFA12, and PBTFA13, featuring 4,7-bis(thien-2-yl)-5,6-difluorobenzo $[c][1,2,5]$ thiadiazole moieties as conjugated units in the polymer backbone with conjugated $t$ TPA-containing moieties as side chains, is illustrated in Figure 1.

\section{PBTFA11}

A solution of $1(0.41 \mathrm{~g}, 1.0 \mathrm{mmol}), 2(0.35 \mathrm{~g}$, $0.50 \mathrm{mmol})$, and $\mathbf{3}(0.25 \mathrm{~g}, 0.50 \mathrm{mmol})$ in dry $o$-DCB $(30 \mathrm{~mL})$ was stirred at room temperature under $\mathrm{N}_{2}$ for $10 \mathrm{~min}$ and then a solution of $\mathrm{Pd}_{2}(\mathrm{dba})_{3}(55 \mathrm{mg}$, $0.040 \mathrm{mmol})$ and $\mathrm{P}(o \text {-tolyl })_{3}(73 \mathrm{mg}, 0.16 \mathrm{mmol})$ in 

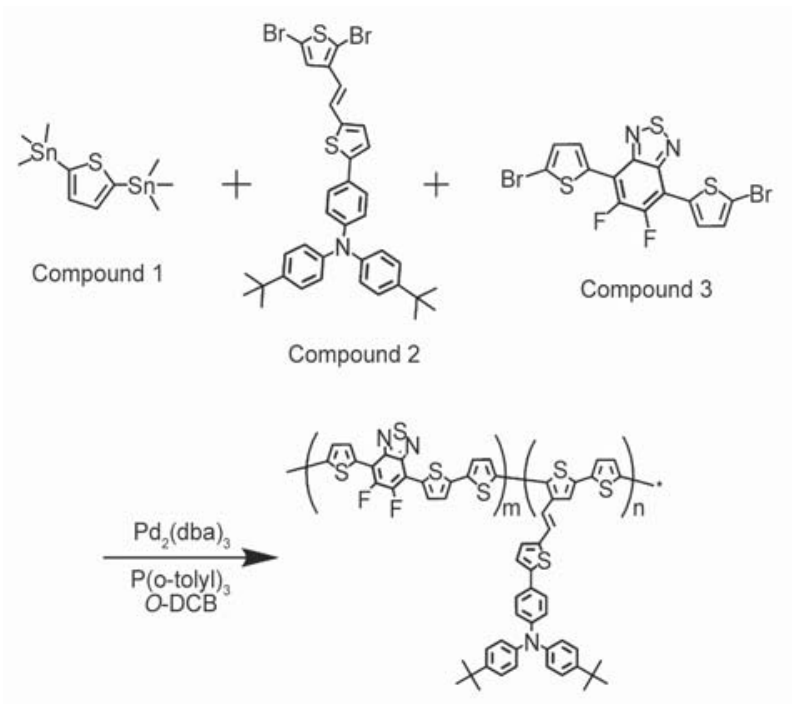

PBTFA11, PBTFA12, PBTFA13

Figure 1. Synthesis of PBTFA11, PBTFA12, and PBTFA13

dry $o$-DCB $(10 \mathrm{~mL})$ was added dropwise. The solution was heated at $120^{\circ} \mathrm{C}$ for $48 \mathrm{~h}$ with stirring. After cooling to room temperature, the solution was poured into $\mathrm{MeOH}(100 \mathrm{~mL})$. The precipitate was filtered into a Soxhlet thimble and extracted with $\mathrm{MeOH}$, hexane, acetone, and $o$-DCB. The polymer PBTFA11 was recovered through concentration of the $o$-DCB fraction under vacuum. Drying under vacuum for $24 \mathrm{~h}$ provided a black solid $(0.05 \mathrm{~g}$, 5.0\%). ${ }^{1} \mathrm{H} \mathrm{NMR}\left(\delta[\mathrm{ppm}], 600 \mathrm{MHz}, \mathrm{CD}_{2} \mathrm{Cl}_{2}\right): 0.76$ $1.42(\mathrm{~m}, 18 \mathrm{H}), 6.40-7.62(\mathrm{~m}, 23 \mathrm{H})$. Anal. Calcd for $\left[\left(\mathrm{C}_{18} \mathrm{H}_{6} \mathrm{~N}_{2} \mathrm{~S}_{4} \mathrm{~F}_{2}\right)\left(\mathrm{C}_{40} \mathrm{H}_{37} \mathrm{NS}_{3}\right) 1.7\right]: \mathrm{C}, 69.64 ; \mathrm{H}, 4.65$; N, 3.50; S, 19.65. Found: C, 69.74; H, 4.59; N, 3.52; S, 19.69 .

\section{PBTFA12}

Using the same procedure as that described for the synthesis of PBTFA11, the reaction of $1(0.41 \mathrm{~g}$, $1.0 \mathrm{mmol}), 2(0.47 \mathrm{~g}, 0.67 \mathrm{mmol})$, and $3(0.16 \mathrm{~g}$, $0.33 \mathrm{mmol})$, provided a black solid $(0.2 \mathrm{~g}, 19.0 \%)$. ${ }^{1} \mathrm{H}$ NMR $\left(\delta[\mathrm{ppm}], 600 \mathrm{MHz}, \mathrm{CD}_{2} \mathrm{Cl}_{2}\right): 0.78-1.40$ (m, 18H), 6.30-7.42 (m, 29H). Anal. Calcd for $\left[\left(\mathrm{C}_{18} \mathrm{H}_{6} \mathrm{~N}_{2} \mathrm{~S}_{4} \mathrm{~F}_{2}\right)\left(\mathrm{C}_{40} \mathrm{H}_{37} \mathrm{NS}_{3}\right) 2.6\right]: \mathrm{C}, 71.55 ; \mathrm{H}, 4.99$; N, 3.15; S, 18.46. Found: C, 71.51; H, 5.02; N, 3.13; S, 18.49 .

\section{PBTFA13}

Using the same procedure as that described for the synthesis of PBTFA11, the reaction of $1(0.41 \mathrm{~g}$, $1.0 \mathrm{mmol}), 2(0.53 \mathrm{~g}, 0.75 \mathrm{mmol})$, and $3(0.12 \mathrm{~g}$, $0.25 \mathrm{mmol})$, provided a black solid $(0.16 \mathrm{~g}, 15.0 \%)$.

${ }^{1} \mathrm{H}$ NMR $\left(\delta[\mathrm{ppm}], 600 \mathrm{MHz}, \mathrm{CD}_{2} \mathrm{Cl}_{2}\right): 0.82-1.37$ (m, 18H), 6.50-7.41 (m, 33H). Anal. Calcd for [( $\left.\left.\mathrm{C}_{18} \mathrm{H}_{6} \mathrm{~N}_{2} \mathrm{~S}_{4} \mathrm{~F}_{2}\right)\left(\mathrm{C}_{40} \mathrm{H}_{37} \mathrm{NS}_{3}\right) 3.8\right]$ : C, 72.88; H, 5.23; N, 2.90; S, 17.61. Found: C, 72.90; H, 5.21; N, 2.94; $\mathrm{S}, 17.58$.

\subsection{Characterization of copolymers}

${ }^{1} \mathrm{H}$ NMR (600 MHz) spectra were recorded using a Varian Unity Inova spectrometer (Agilent, California, USA). The average molecular weights of the polymers were measured through gel permeation chromatography (GPC) on a Waters chromatography system (Waters 717 Plus Autosampler, Waters Co., Milford, MA, USA) equipped with two Waters Styragel linear columns; polystyrene standards were used, with THF as the eluent. The glass transition temperatures $\left(T_{\mathrm{g}}\right)$ and thermal decomposition temperatures ( $T_{\mathrm{d}}$; temperature at which weight loss reached $5 \%$ ) of the copolymers were measured using differential scanning calorimetry (DSC-2010; TA Instruments, New Castle, DE, USA) and thermogravimetric analysis (TGA-2050; TA Instruments, New Castle, DE, USA), respectively. Both analyses were performed under $\mathrm{N}_{2}$ atmospheres at scanning (both heating and cooling) rates of $10^{\circ} \mathrm{C} \cdot \mathrm{min}^{-1}$. The temperatures at the intercepts of the curves in the thermograms (endothermic, exothermic, or weight loss) with the leading baseline were taken as estimates of the values of $T_{\mathrm{g}}$ and $T_{\mathrm{d}}$. Absorption spectra were measured using a Hitachi U3010 UV-Vis spectrometer (Hitachi High-Tech Co., Tokyo, Japan); dilute $o$-DCB solutions of the PTs were filtered through a $0.45 \mu \mathrm{m}$ filter to remove insoluble materials prior to spectral measurement. The redox potentials of the polymers were determined in anhydrous $\mathrm{N}_{2}$-saturated $0.1 \mathrm{M}$ $\mathrm{Bu}_{4} \mathrm{NClO}_{4}$ in MeCN using a CHI 611D electrochemical analyzer (Ch Instruments, Texas, USA; scanning rate: $\left.50 \mathrm{mV} \cdot \mathrm{s}^{-1}\right)$ equipped with Pt electrodes and an $\mathrm{Ag} / \mathrm{Ag}^{+}\left(0.10 \mathrm{M} \mathrm{AgNO}_{3}\right.$ in $\left.\mathrm{MeCN}\right)$ reference electrode. $\mathrm{Bu}_{4} \mathrm{NClO}_{4}(98 \%$, TCI) was recrystallized three times from $\mathrm{MeOH}$ and water $(1: 1)$ and then dried at $100^{\circ} \mathrm{C}$ under reduced pressure. A Pt plate coated with a thin polymer film was used as the working electrode; a Pt wire and an $\mathrm{Ag} / \mathrm{Ag}^{+}$electrode were used as the counter and reference electrodes, respectively. The electrochemical potential was calibrated against ferrocene/ferrocenium. The morphologies of the films prepared from $\mathrm{PT} / \mathrm{PC}_{61} \mathrm{BM}$ (or $\mathrm{PC}_{71} \mathrm{BM}$ ) blends were studied using atomic force microscopy (AFM, SII SPA400; Seiko Instruments, Inc., Chiba, Japan; operated in tapping mode) and transmission 
electron microscopy (TEM, JEM-1400; JEOL Taiwan semiconductors Ltd., Hsinchu, Taiwan).

\subsection{Fabrication and characterization of PSCs}

The PSCs fabricated in this study had structures of ITo-coated glass/HTM/photoactive layer/Ca $(20 \mathrm{~nm}) /$ $\mathrm{Al}(100 \mathrm{~nm})$, where the photoactive layer comprised an interpenetrating network of $\mathrm{PT}$ and a fullerene derivative $\left(\mathrm{PC}_{61} \mathrm{BM}\right.$ or $\mathrm{PC}_{71} \mathrm{BM}$; Nano Carbon LLC, Warsaw, Poland). ITO-coated glass (sheet resistance: $20 \Omega^{-2}$ ) was purchased from Applied Film (AF Co., Alzenau, Germany). $\mathrm{PC}_{61} \mathrm{BM}$ and $\mathrm{PC}_{71} \mathrm{BM}$ were purchased from Nanocarbon and used as received. The PSCs were fabricated as follows: glass substrates with patterned ITO electrodes were washed well and then cleaned through $\mathrm{O}_{2}$ plasma treatment. A thin film of the HTM, poly(3,4-ethylenedioxythiophene) doped with polystyrenesulfonate (PEDOT:PSS, AI4083; Heraeus Clevios Co., Hanau, Germany), was deposited on the ITO layer through spin-casting. The sample was dried at $150^{\circ} \mathrm{C}$ for $30 \mathrm{~min}$ in a glove box. A solution of $\mathrm{PT}$ and $\mathrm{PC}_{61} \mathrm{BM}$ (or $\mathrm{PC}_{71} \mathrm{BM}$ ) $\left(30 \mathrm{mg} \cdot \mathrm{mL}^{-1}\right)$ in $o$-DCB was stirred overnight, then filtered through a $0.2 \mu \mathrm{m}$ polytetrafluoroethylene (PTFE) filter and spin-coated (1500 rpm, $30 \mathrm{~s}$ ) onto the HTM layer to prepare the $\mathrm{PT} / \mathrm{PC}_{61} \mathrm{BM}$ (or $\mathrm{PC}_{71} \mathrm{BM}$ ) composite filmbased photoactive layer. The sample was dried at $110^{\circ} \mathrm{C}$ for $10 \mathrm{~min}$ in a glove box. In a high-vacuum chamber, the $\mathrm{Ca} / \mathrm{Al}$-based cathode was thermally deposited onto the $\mathrm{PT} / \mathrm{PC}_{61} \mathrm{BM}$ (or $\mathrm{PC}_{71} \mathrm{BM}$ ) composite layer. The active area of the PSC was $0.04 \mathrm{~cm}^{2}$. After electrode deposition, the PSC was encapsulated. The cathode deposition rate was determined using a quartz thickness monitor (STM-100/MF; Sycon Instruments, East Syracuse, NY, USA). The thickness of thin films was measured using a surface texture analysis system (Dektak 3030ST; Veeco Instruments, Inc., Hsinchu, Taiwan). The PV properties of the PSCs were measured, using a programmable electrometer equipped with current and voltage sources (Keithley 2400; Keithley Instruments, Inc., Cleveland, OH, USA), under illumination with solar-simulating light $\left(100 \mathrm{~mW} \cdot \mathrm{cm}^{-2}\right)$ from an AM1.5 solar simulator (NewPort Oriel 96000; Newport Corporation Taiwan, Taipei, Taiwan).

\section{Results and discussion}

\subsection{Characterization of PTs}

The conjugated PTs were synthesized through Stille coupling of the distannane $\mathbf{1}$ with the dibromides $\mathbf{2}$ and 3. The chemical structures of the monomers were confirmed using ${ }^{1} \mathrm{H}$ NMR spectroscopy and elemental analysis. The repeat unit ratios ( $m / n$; see Figure 1) of the PTs PBTFA11, PBTFA12, and PTBFA13 were modulated by controlling the feed ratio of the DFBT derivative (3) and the conjugated pendant $t$ TPA-containing thiophene derivative (2). For PBTFA11, PBTFA12, and PTBFA13, the actual values of $m / n$ were determined from the relative integral areas of the peaks at 6.30-7.60 ppm (representing protons of the vinylene, phenyl, and thiophene groups) and 0.91.3 (representing protons of the tert-butyl groups) in the ${ }^{1} \mathrm{H}$ NMR spectra of the copolymers; they were approximately $1: 1.7,1: 2.6$, and $1: 3.8$, respectively. For the PTs, the content of DFBT moieties in the polymer backbone was lower than the feed content of $\mathbf{3}$ in the reaction mixture during polymerization, presumably because of the relatively poor solubility of DFBT in the reaction solution. In addition, through GPC using THF as the eluent and polystyrene internal standards, we determined the number-average molecular weights $\left(M_{\mathrm{n}}\right)$ and weight-average molecular weights $\left(M_{\mathrm{w}}\right)$ of the conjugated PTs. Table 1 reveals that the values of $M \mathrm{n}$ and $M_{\mathrm{w}}$ of the conjugated polymers were in the ranges $6.5-8.2$ and $14.5-$ $30.2 \mathrm{~kg} \cdot \mathrm{mol}^{-1}$, respectively. The introduction of the DFBT unit into the polymer backbone usually brings about the PTs with poor solubility [36, 42]. Moreover, the poor solubility of the polymers might be possibly due to the absence of the long alkyl side chain on the polymer backbone [38]. The early termination of the propagation of the polymer chains resulted from poor solubility of the polymers in the reaction solution $[29,50]$. As a result, the PTs exhibited low average molecular weights. Apart from that, the reaction product of PTs was purified by Soxhlet extraction with different organic solvents. The oligomers of PT were therefore removed. As a result, low yields of reaction products were obtained for these PTs.

Table 1. molecular weights and thermal properties of the PTs

\begin{tabular}{|c|c|c|c|c|}
\hline PT & $\begin{array}{c}\boldsymbol{M}_{\mathbf{n}} \\
{\left[\mathbf{k g} \cdot \mathbf{m o l}^{-\mathbf{1}}\right]}\end{array}$ & $\begin{array}{c}\boldsymbol{M}_{\mathbf{w}} \\
{\left[\mathbf{k g} \cdot \mathbf{m o l}^{-\mathbf{1}}\right]}\end{array}$ & $\begin{array}{c}\boldsymbol{T}_{\mathbf{g}}{ }^{*} \\
{\left[{ }^{\circ} \mathbf{C}\right]}\end{array}$ & $\begin{array}{c}\boldsymbol{T}_{\mathbf{d}}{ }^{* *} \\
{\left[{ }^{\circ} \mathbf{C}\right]}\end{array}$ \\
\hline PBTFA13 & 8.2 & 30.2 & 118.5 & 245.5 \\
\hline PBTFA12 & 7.3 & 20.2 & 124.2 & 268.6 \\
\hline PBTFA11 & 6.5 & 14.5 & $-{ }^{* * *}$ & 278.1 \\
\hline
\end{tabular}

${ }^{*} T_{\mathrm{g}}$ : Measured at a heating rate of $10^{\circ} \mathrm{C} \cdot \mathrm{min}^{-1}$.

${ }^{* *} T_{\mathrm{d}}$ : Temperature at which weight loss reached $5 \%$.

${ }^{* * *}$ Not detectable. 

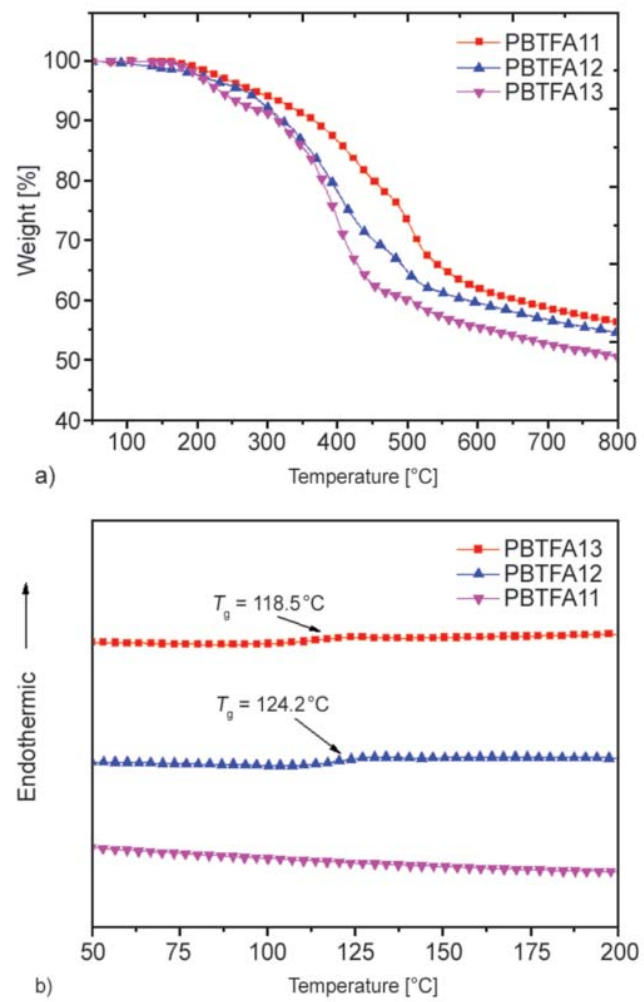

Figure 2. TGA (a) and DSC (b) thermograms of PBTFA11, PBTFA12, and PBTFA13

The operational stability of a PSC is closely related to the thermal stability of its conjugated polymer. Thus, high values of $T_{\mathrm{g}}$ and $T_{\mathrm{d}}$ are desirable. We used DSC and TGA to determine the thermal properties of the PTs. TGA and DSC thermograms of PTs are shown in Figure 2. The values of $T_{\mathrm{d}}$ for PBTFA13, PBTFA12, and PTBFA11 were 245.5, 268.6, and $278.1^{\circ} \mathrm{C}$, respectively. The thermal stability of the DFBT derivative $3\left(T_{\mathrm{d}}=325^{\circ} \mathrm{C}\right)$ was higher than that of the conjugated pendant compound $2\left(T_{\mathrm{d}}=275^{\circ} \mathrm{C}\right)$. As a result, the thermal stability of the PTs increased upon increasing the content of the DFBT derivative. We determined the glass transition temperatures from the second round of DSC heating scans. No glass transition was evident for PBTFA11. The values of $\mathrm{Tg}$ for PBTFA13 and PBTFA12 were 118.5 and $124.2^{\circ} \mathrm{C}$, respectively. High $T_{\mathrm{g}}\left(>100^{\circ} \mathrm{C}\right)$ of PTs make them suitable for PSC applications.

\subsection{Optical properties of PTs}

Figure 3 displays the normalized UV-Vis absorption spectra of the DFBT-based PTs in $o$-DCB solution and as solid films; Table 2 summarizes the corresponding absorption data. The absorption bands of the DFBT-based PTs in $o$-DCB ranged from 325 to $800 \mathrm{~nm}$, with each polymer providing two broad

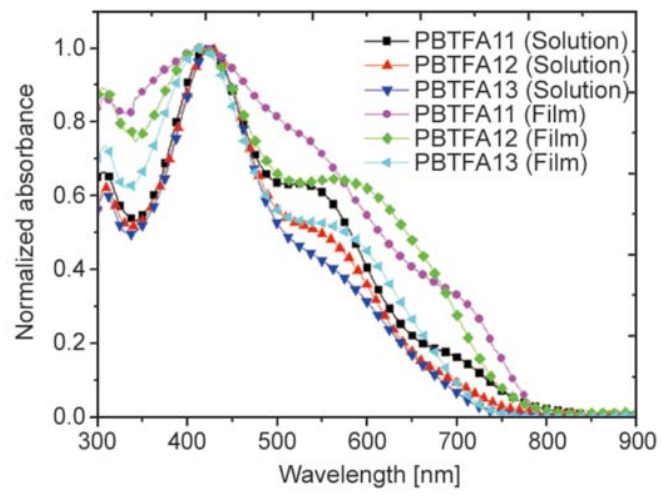

Figure 3. Normalized UV-Vis absorption spectra of the PTs (a) in $o$-DCB solution and (b) as thin films

absorption bands. We attribute the first absorption band in the range $325-500 \mathrm{~nm}$ to the $\mathrm{n}-\pi *$ transitions of the conjugated side chains and the $\pi-\pi^{*}$ transitions of the conjugated main chain [29]. The second absorption band in the range $500-800 \mathrm{~nm}$ originated from intramolecular charge transfer (ICT) between the thiophene derivative-based donor units and the DFBT-based acceptor units [30]. Moreover, the absorption intensity of the second absorption band increased upon increasing the content of DFBT units in the copolymer, both in solution and in the thin film state. In addition, the red-shifts and full widths at halfmaximum of the absorption bands of the copolymers in the films were greater than those in solution, presumably because of strong noncovalent interactions (e.g., $\pi$-stacking) between the polymer backbones and conjugated pendant units $[30,51]$. Notably, the spectra of PBTFA11 in solution and as a thin film exhibited an additional shoulder peak in the range from 680 to $780 \mathrm{~nm}$. The incorporation of a higher content of the DFBT derivative decreased the steric bulk of the conjugated pendant units and could, therefore, planarize the polymer main chain to some extent [36]. As a result, the absorption wavelengths of the polymers containing higher DFBT contents exhibited longer absorption onsets. Accordingly, PBTFA11 displayed the absorption shoulder peak. On the other hand, the intensity of the second absorption band was lower than that of the first absorption band for the PTs, presumably because of the low content of DFBT units in the polymer backbone. In addition, we used the onset wavelengths of the absorption bands to determine the band gap energies $\left(E_{\mathrm{g}}\right)$ of the conjugated polymers in the thin film state. The values of $E_{\mathrm{g}}$ for PBTFA13, PBTFA12, and PBTFA11 were $1.69,1.59$, and $1.57 \mathrm{eV}$, respectively. Lower values of $E_{\mathrm{g}}$ were observed for the copolymers containing higher contents 
of DFBT units. Broader absorption and a lower band gap energy typically improve the solar light absorption efficiency of the photo-energy conversion layer in PSCs, resulting in the generation of larger photocurrents.

Figure 4 presents normalized UV-Vis absorption spectra of the $\mathrm{PT} / \mathrm{PC}_{61} \mathrm{BM}$ composite films. The absorption band of the DFBT-based conjugated copolymer ranged from 375 to $800 \mathrm{~nm}$, while the absorption band of $\mathrm{PC}_{61} \mathrm{BM}$ ranged from 300 to $375 \mathrm{~nm}$. The maximal absorption intensities of the conjugated copolymer and $\mathrm{PC}_{61} \mathrm{BM}$ were near 420 and $325 \mathrm{~nm}$, respectively. Moreover, the absorption intensity of the conjugated polymer decreased upon increasing the
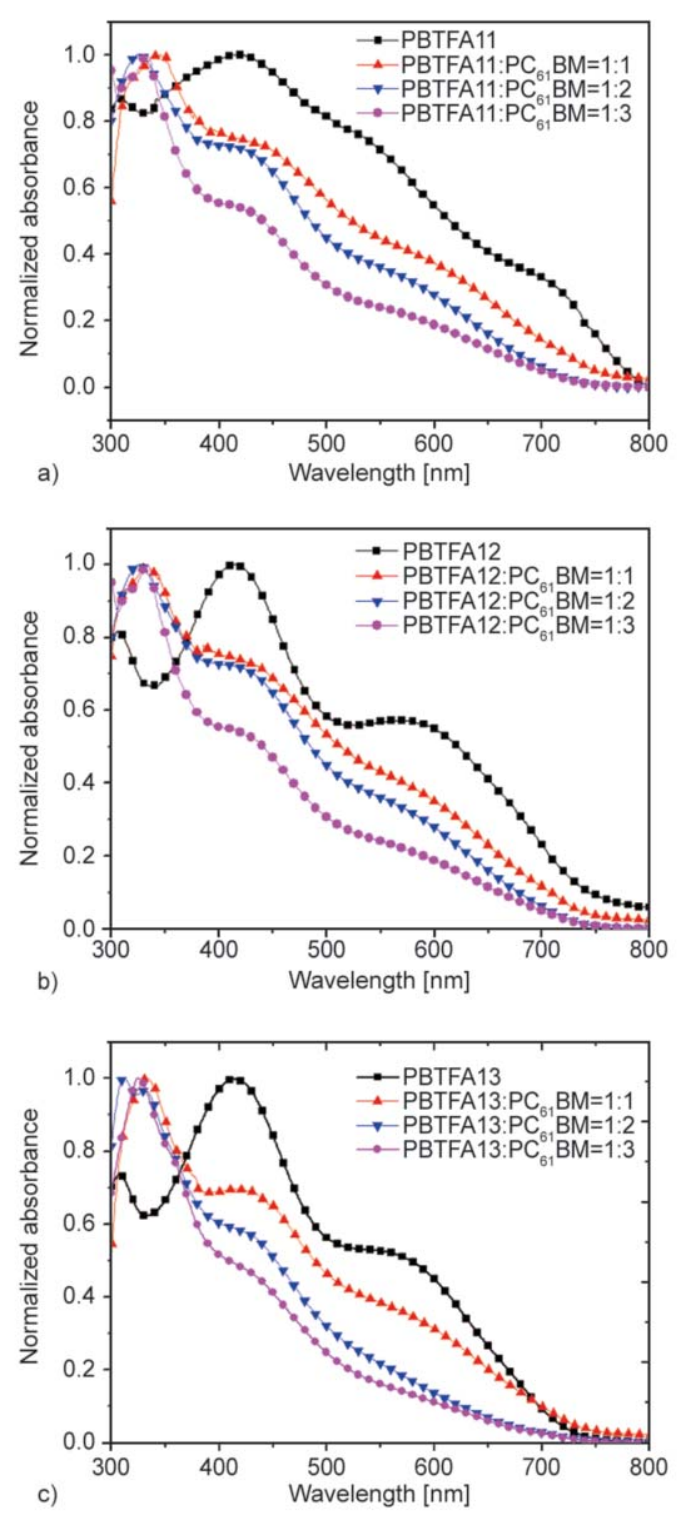

Figure 4. Normalized UV-Vis absorption spectra of (a) PBTFA11/PC ${ }_{61} \mathrm{BM}$, (b) PBTFA12/PC ${ }_{61} \mathrm{BM}$, and (c) PBTFA13/PC 61 BM blend films
$\mathrm{PC}_{61} \mathrm{BM}$ content for the DFBT-based PT/PC ${ }_{61} \mathrm{BM}$ composite films.

\subsection{Electrochemical properties of PTs}

We employed CV to investigate the electrochemical behavior of our PTs and to estimate the energy levels of their HOMOs. Figure 5 displays the oxidation behavior in the CV curves of the PTs. Table 2 summarizes the electrochemical properties of the copolymers. The oxidation potentials $\left(E_{\mathrm{on}}^{\mathrm{ox}}\right)$ of PBTFA13, PBTFA12, and PBTFA11 were $0.52,0.54$, and $0.59 \mathrm{~V}$, respectively. From those values, we calculated the HOMO energy levels of the copolymers according to the Equation (1):

$\mathrm{HOMO}=-e\left(E_{\mathrm{on}}^{\mathrm{ox}}-E_{\mathrm{on}}^{\mathrm{ox}}\right.$, ferrocene +4.71$)[\mathrm{eV}]$

where $4.71 \mathrm{eV}$ is the energy level of ferrocene below the vacuum level and the value of $E_{\mathrm{on}}^{\mathrm{ox}}$ of ferrocene/ ferrocene $^{+}$is $0.09 \mathrm{~V}$ in $0.1 \mathrm{M} \mathrm{Bu}_{4} \mathrm{NClO}_{4} / \mathrm{MeCN}$. The HOMO energy levels obtained for PBTFA13, PBTFA12, and PBTFA11 were $-5.23,-5.25$, and $5.30 \mathrm{eV}$, respectively. Higher HOMO energy levels were observed for the PTs containing higher contents of the TPA-containing conjugated pendant units; these values generally correlate with the electron-donating ability of the polymers [29]. In addition, because we observed no reversible n-doping process in the CV spectra, we estimated the LUMO energy levels from the HOMO energy levels and the values of $E_{\mathrm{g}}$ from the UV-Vis absorption spectra, using the Equation (2):

$\mathrm{LUMO}=\mathrm{HOMO}+E_{\mathrm{g}}[\mathrm{eV}]$

The LUMO levels obtained were $-3.54 \mathrm{eV}$ for PBTFA13, $-3.66 \mathrm{eV}$ for PBTFA12, and $-3.73 \mathrm{eV}$ for

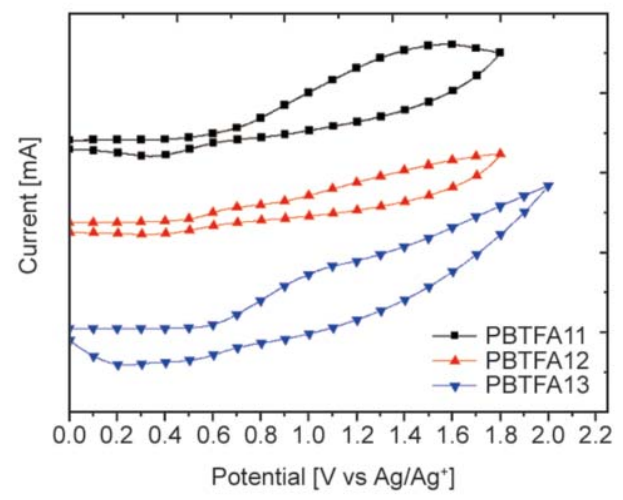

Figure 5. Cyclic voltammograms of PBTFA11, PBTFA12, and PBTFA13 
Table 2. Optical properties, electrochemical onset potentials, and electronic energy levels of the PTs

\begin{tabular}{|c|c|c|c|c|c|c|}
\hline \multicolumn{1}{|c|}{ PTs } & $\begin{array}{c}\lambda_{\mathbf{m a x}}^{\text {abs }} \\
{[\mathbf{n m}]}\end{array}$ & $\begin{array}{c}\lambda_{\mathbf{m a x}}^{\text {abs }} \\
{[\mathbf{n m}]}\end{array}$ & $\begin{array}{c}\boldsymbol{E}_{\mathbf{g}}^{\text {opt }} \\
{[\mathbf{e V}]}\end{array}$ & $\begin{array}{c}\boldsymbol{E}_{\mathbf{0}}^{* * *} \\
{[\mathbf{V}]}\end{array}$ & $\begin{array}{c}\text { HOMO } \\
{[\mathbf{e V}]}\end{array}$ & $\begin{array}{c}\text { LUMO } \\
{[\mathbf{e V}]}\end{array}$ \\
\hline PBTFA13 & 427,550 & 413,578 & 1.69 & 0.52 & -5.23 & -3.54 \\
\hline PBTFA12 & 425,550 & 414,585 & 1.59 & 0.54 & -5.25 & -3.66 \\
\hline PBTFA11 & $422,540,590$ & $422,550,710$ & 1.57 & 0.59 & -5.30 & -3.73 \\
\hline
\end{tabular}

${ }^{*}$ Maximal absorption wavelength of the polymer in solution.

${ }^{* *}$ Maximal absorption wavelength of the polymer as a thin film.

${ }^{* * *}$ Calculated from the onset absorption $\left(\lambda_{\max }^{\text {abs }}\right)$ of the polymer thin film: $E_{\mathrm{g}}=1240 / \lambda_{\text {onset }}$

PBTFA11. Thus, lower LUMO energy levels were obtained for the PTs containing higher contents of the electron-deficient DFBT units. Accordingly, the electrochemical properties of these PTs could be tuned by varying the content of the electron-accepting DFBT unit in the polymer backbone. In general, the HOMO energy level of the conjugated polymer is a parameter that affects the performance of BHJtype cells. High open-circuit voltages $\left(V_{\mathrm{OC}}\right)$ are typically obtained for PSCs fabricated from conjugated polymers with low HOMO energy levels [29].

\subsection{Morphologies of thin films of $\mathrm{PT} / \mathrm{PC}_{61} \mathrm{BM}$ blends}

The performance of a PSC is strongly dependent on the morphology of its conjugated polymer/fullerene derivative composite film [52-54]. To avoid recombination of excitons, the morphology of the $\mathrm{P} / \mathrm{N}$ heterojunction phase must be controlled at the nanoscale level [29]. We used AFM to investigate the compatibility and morphologies of our conjugated polymer $/ \mathrm{PC}_{61} \mathrm{BM}$ composite films. Figure 6 displays topographic and phase-contrast images of $\mathrm{PBTFA}_{13} /$ $\mathrm{PC}_{61} \mathrm{BM}$ composite films $(1: 1,1: 2$, and $1: 3, \mathrm{w} / \mathrm{w})$ after annealing at $110^{\circ} \mathrm{C}$ for $10 \mathrm{~min}$; Figures 7 and 8 present the corresponding images of the PBTFA12/ $\mathrm{PC}_{61} \mathrm{BM}$ and PBTFA11/PC ${ }_{61} \mathrm{BM}$ composite films $(1: 1,1: 2$, and $1: 3, \mathrm{w} / \mathrm{w})$, respectively. The phase-contrast images reveal that the distribution of the $\mathrm{PC}_{61} \mathrm{BM}$ units in the polymers was uniform for the DFBTbased $\mathrm{PT} / \mathrm{PC}_{61} \mathrm{BM}$ composite films. In each case, we observed a phase-separated interpenetrating network

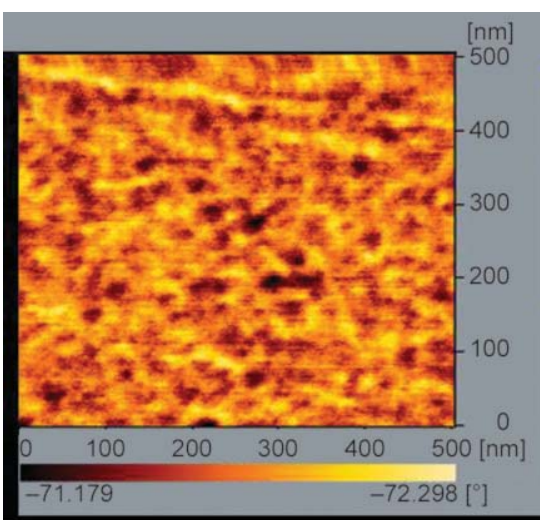

a) 1:1

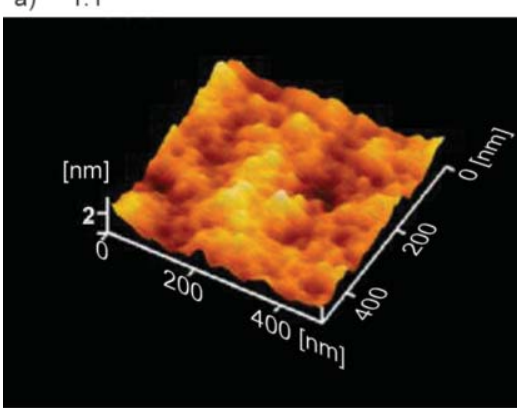

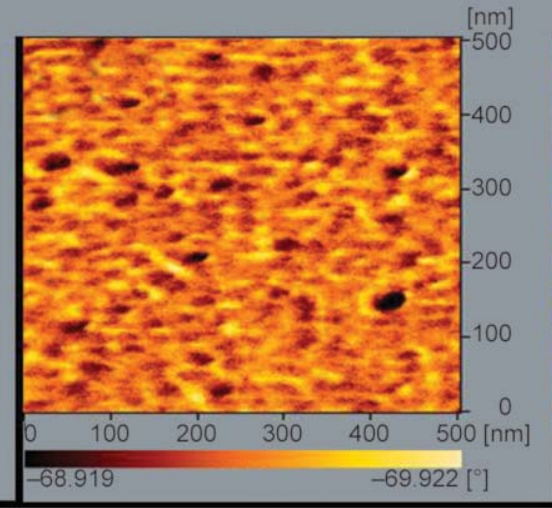

b) $1: 2$

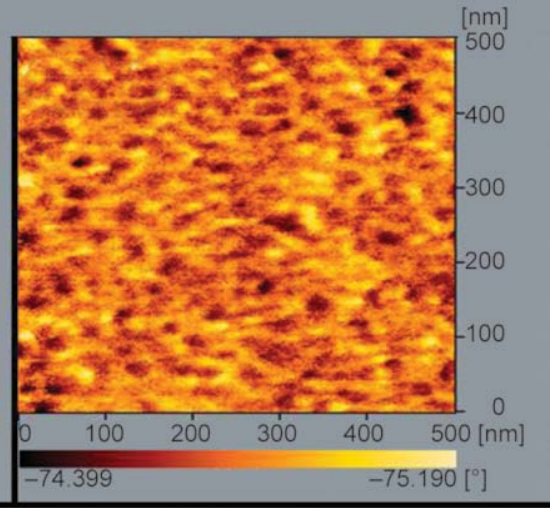

c) $1: 3$

d) $1: 1$
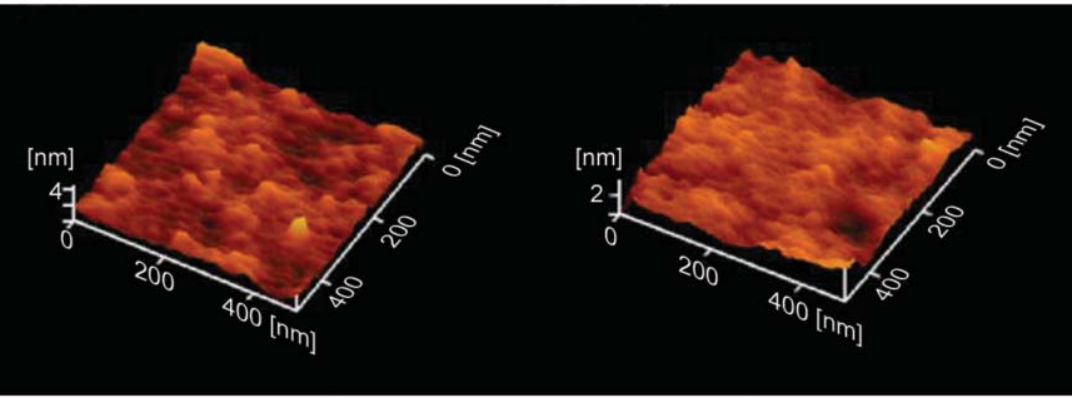

Figure 6. Tapping-mode AFM $(\mathrm{a}-\mathrm{c})$ topographic and $(\mathrm{d}-\mathrm{f})$ phase images of PBTFA13 blend films $[(\mathrm{a}, \mathrm{d}) \mathrm{w} / \mathrm{w}=1: 1$; $(\mathrm{b}, \mathrm{e}) \mathrm{w} / \mathrm{w}=1: 2 ;(\mathrm{c}, \mathrm{f}) \mathrm{w} / \mathrm{w}=1: 3$ ] that had been subjected to annealing at $110^{\circ} \mathrm{C}$ for $10 \mathrm{~min}$ 
with sizable $\mathrm{PC}_{61} \mathrm{BM}$ domains. Some degree of phase separation is critical for efficient formation of free

carriers to provide PSCs displaying optimal PV properties.
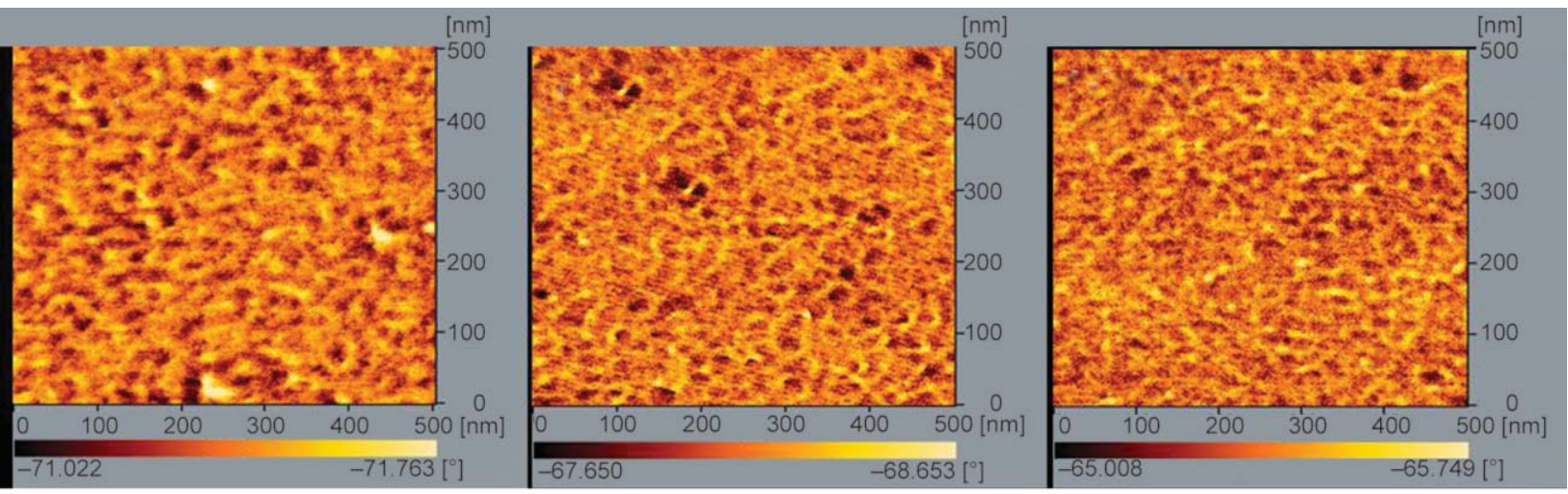

a) $1: 1$

b) $1: 2$

c) $1: 3$

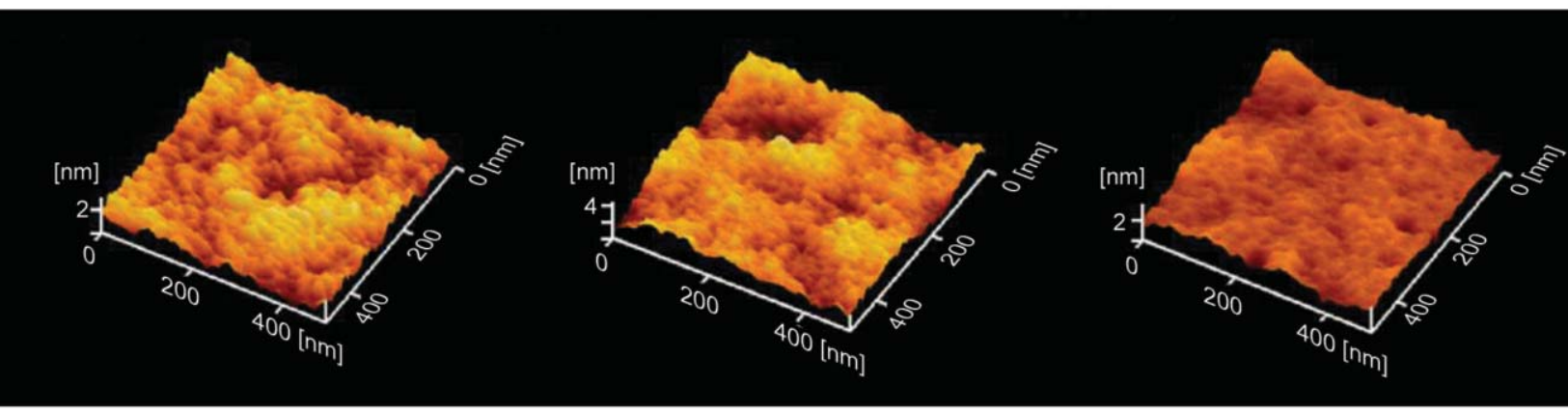

d) $1: 1$

e) $1: 2$

f) $1: 3$

Figure 7. Tapping-mode AFM (a-c) topographic and $(d-f)$ phase images of PBTFA 12 blend films $[(a, d) w / w=1: 1$; $(b, e) w / w=1: 2 ;(c, f) w / w=1: 3]$ that had been subjected to annealing at $110^{\circ} \mathrm{C}$ for $10 \mathrm{~min}$
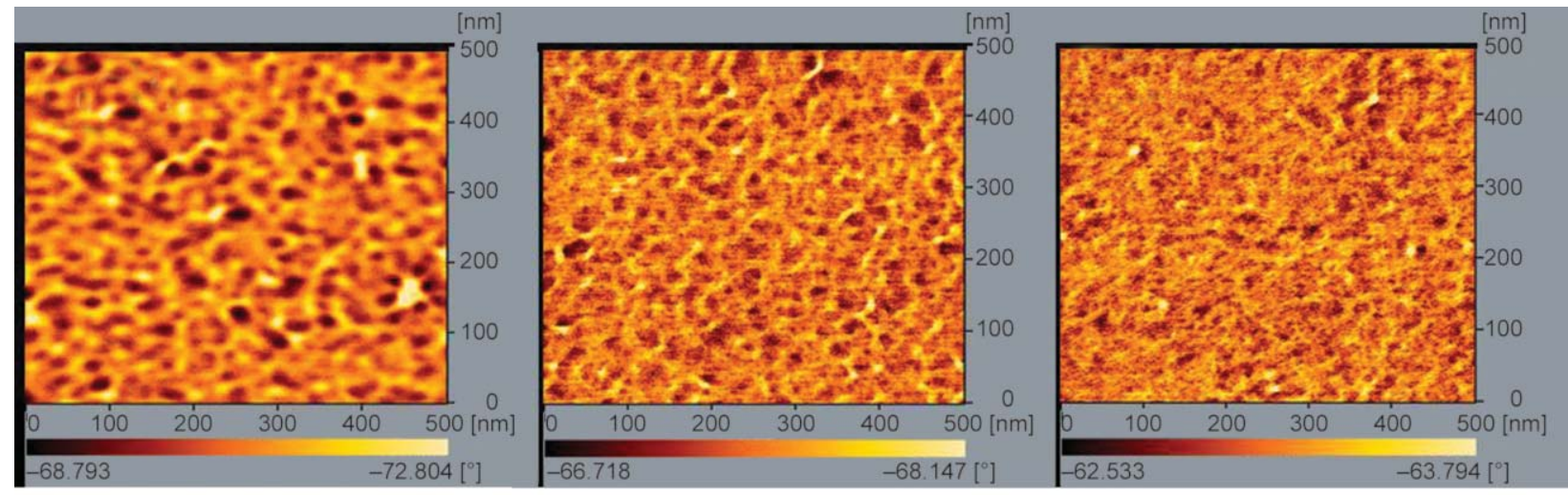

a) $1: 1$

b) $1: 2$

c) $1: 3$

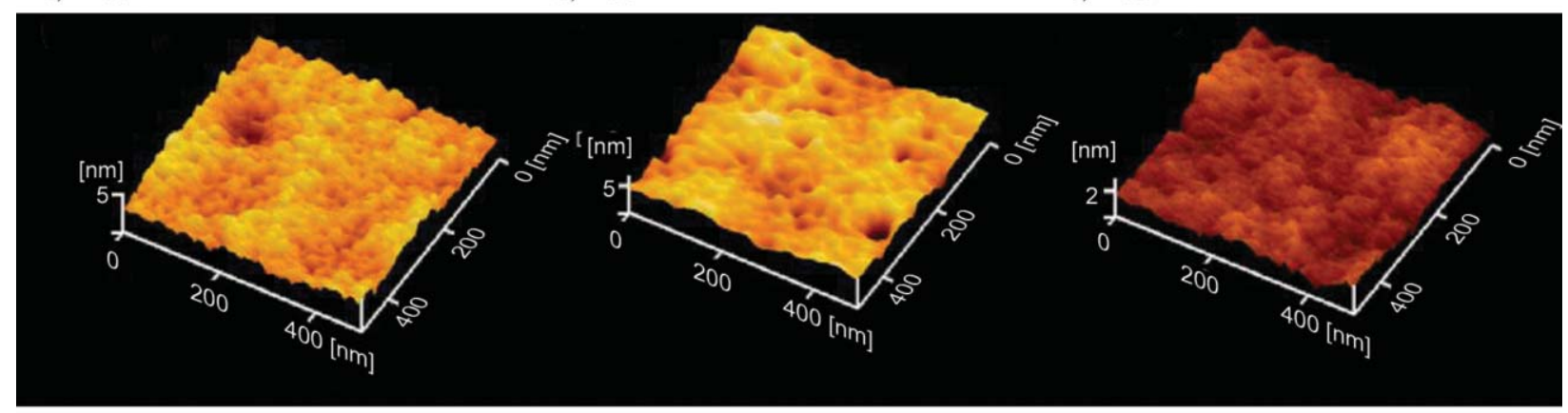

d) 1:1

e) $1: 2$

f) $1: 3$

Figure 8. Tapping-mode AFM $(a-c)$ topographic and $(d-f)$ phase images of PBTFA11 blend films $[(a, d) w / w=1: 1$; $(\mathrm{b}, \mathrm{e}) \mathrm{w} / \mathrm{w}=1: 2 ;(\mathrm{c}, \mathrm{f}) \mathrm{w} / \mathrm{w}=1: 3$ ] that had been subjected to annealing at $110^{\circ} \mathrm{C}$ for $10 \mathrm{~min}$ 


\subsection{PV properties of PSCs incorporating PT/PC ${ }_{61}$ BM Films}

We fabricated PSCs incorporating $\mathrm{PT} / \mathrm{PC}_{61} \mathrm{BM}$ and $\mathrm{PT} / \mathrm{PC}_{71} \mathrm{BM}$ blends as photoactive layers, prepared through spin-coating. Figure 9a presents the best PV performance of these PSCs; the statistic values of $\mathrm{PCE}$, along with open-circuit voltages $\left(V_{\mathrm{OC}}\right)$, shortcircuit current densities $\left(J_{\mathrm{SC}}\right)$, fill factors (FFs), and PCEs, are summarized in Table 3. Three runs of PV evaluation test were performed for each PSC sample. In general, high values of $V_{\mathrm{OC}}$ are typically obtained for PSCs fabricated from conjugated polymers having low HOMO energy levels. We found, however, that the values of $V_{\mathrm{OC}}$ for the PBTFA13/ $\mathrm{PC}_{61} \mathrm{BM}$ based PSCs were higher than those of the PBTFA12/ $\mathrm{PC}_{61} \mathrm{BM}$ - and PBTFA11/PC ${ }_{61} \mathrm{BM}$-based PSCs, even though the HOMO energy level of PBTFA13 was higher than those of PBTFA12 and PBTFA11. This phenomenon was a result of PBTFA13 having a

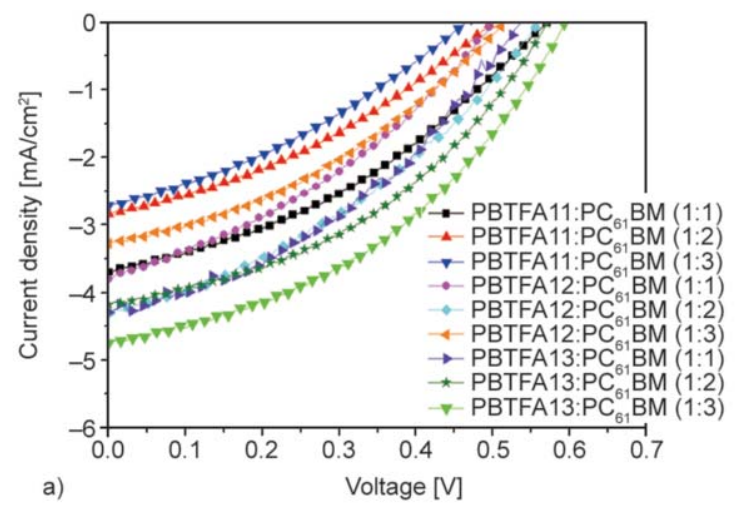

LUMO energy level higher than those of PBTFA12 and PBTFA11. Thus, there must have been a relatively strong driving force for dissociation of excitons at the BHJ interface of the PBTFA13/ $\mathrm{PC}_{61} \mathrm{BM}$ blend. Consequently, the lower degree of charge recombination loss resulted in the relatively higher values of $V_{\mathrm{OC}}$ for the PSCs based on the PBTFA13/ $\mathrm{PC}_{61} \mathrm{BM}$ blend films $[55,56]$. Moreover, the values of $J_{\mathrm{SC}}$ of the PSCs incorporating PBTFA13/ $\mathrm{PC}_{61} \mathrm{BM}$ blends were higher than those of the PSCs based on PBTFA12/PC ${ }_{61} \mathrm{BM}$ and PBTFA11/PC ${ }_{61} \mathrm{BM}$. Therefore, the PV properties of the PBTFA13/ $\mathrm{PC}_{61} \mathrm{BM}$ based PSCs (PSC I-1-PSC I-3) were superior to those of the PBTFA12/PC ${ }_{61} \mathrm{BM}$-(PSC II-1-PSC II-3) and PBTFA11/PC ${ }_{61}$ BM-based (PSC III-1-PSC III-3) PSCs. On the other hand, the optimal compositions of $\mathrm{PT}$ to $\mathrm{PC}_{61} \mathrm{BM}$ for the PBTFA13/ $\mathrm{PC}_{61} \mathrm{BM}$, PBTFA12/PC ${ }_{61} \mathrm{BM}$, and PBTFA11/PC ${ }_{61} \mathrm{BM}$ based PSCs were approximately 1:3, 1:2, and 1:1 (w/w),

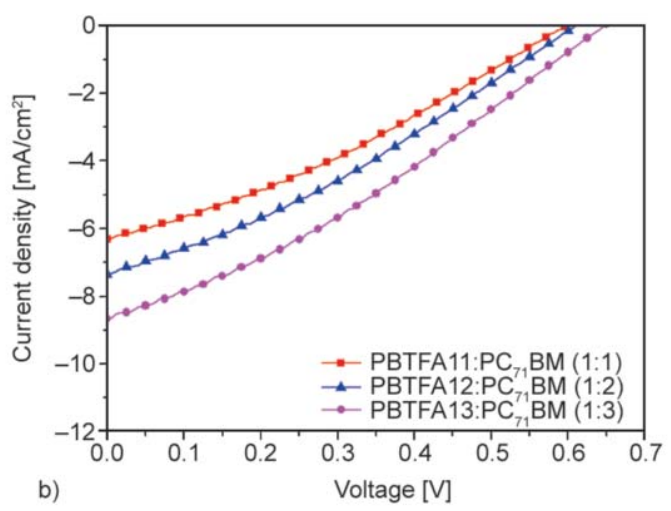

Figure 9. Current density-potential characteristics of illuminated (AM 1.5G, $100 \mathrm{~mW} / \mathrm{cm}^{2}$ ) PT/PC ${ }_{61} \mathrm{BM}-$ and $\mathrm{PT} / \mathrm{PC}{ }_{71} \mathrm{BM}-$ based solar cells under the best conditions, a) $\mathrm{PT} / \mathrm{PC}_{61} \mathrm{BM}$-based cells and b) $\mathrm{PT} / \mathrm{PC}_{71} \mathrm{BM}$-based cells

Table 3. Photovoltaic performance of PSCs of conventional structure prepared with $\mathrm{PT} / \mathrm{PC}_{61} \mathrm{BM}$ and $\mathrm{PT} / \mathrm{PC}_{71} \mathrm{BM}_{\text {photoactive }}$ layers

\begin{tabular}{|c|c|c|c|c|c|c|c|}
\hline PSC $^{*}$ & Photoactive layer & $\begin{array}{c}\mathrm{PT} / \mathrm{PC}_{61} \mathrm{BM}\left(\text { or } \mathrm{PC}_{71} \mathrm{BM}\right) \\
{[\mathrm{w} / \mathrm{w}]}\end{array}$ & $\begin{array}{l}V_{\mathrm{OC}} \\
{[\mathrm{V}]}\end{array}$ & $\begin{array}{c}J_{\mathrm{SC}} \\
{\left[\mathrm{mA} \cdot \mathbf{c m}^{-2}\right]}\end{array}$ & FF & $\begin{array}{l}\text { PCE } \\
{[\%]}\end{array}$ & $\begin{array}{c}\text { Best PCE } \\
{[\%]}\end{array}$ \\
\hline PSC I-1 & PBTFA13/PC ${ }_{61} \mathrm{BM}$ & $1: 1$ & $0.52 \pm 0.02$ & $4.25 \pm 0.03$ & $0.38 \pm 0.02$ & $0.84 \pm 0.02$ & 0.86 \\
\hline PSC I-2 & PBTFA13/PC ${ }_{61} \mathrm{BM}$ & $1: 2$ & $0.56 \pm 0.03$ & $4.21 \pm 0.02$ & $0.40 \pm 0.02$ & $0.94 \pm 0.03$ & 0.97 \\
\hline PSC I-3 & PBTFA13/PC ${ }_{61} \mathrm{BM}$ & $1: 3$ & $0.58 \pm 0.03$ & $4.72 \pm 0.03$ & $0.46 \pm 0.01$ & $1.27 \pm 0.05$ & 1.32 \\
\hline PSC II-1 & PBTFA12/PC 61 BM & $1: 1$ & $0.49 \pm 0.02$ & $3.74 \pm 0.03$ & $0.34 \pm 0.01$ & $0.62 \pm 0.04$ & 0.66 \\
\hline PSC II-2 & PBTFA12/PC 61 BM & $1: 2$ & $0.54 \pm 0.02$ & $4.30 \pm 0.01$ & $0.35 \pm 0.02$ & $0.81 \pm 0.06$ & 0.87 \\
\hline PSC II-3 & PBTFA12/PC ${ }_{61} \mathrm{BM}$ & $1: 3$ & $0.51 \pm 0.01$ & $3.20 \pm 0.02$ & $0.35 \pm 0.02$ & $0.57 \pm 0.02$ & 0.59 \\
\hline PSC III-1 & PBTFA11/PC ${ }_{61} \mathrm{BM}$ & $1: 1$ & $0.56 \pm 0.02$ & $3.77 \pm 0.03$ & $0.36 \pm 0.03$ & $0.76 \pm 0.03$ & 0.79 \\
\hline PSC III-2 & PBTFA11/PC ${ }_{61} \mathrm{BM}$ & $1: 2$ & $0.49 \pm 0.02$ & $2.80 \pm 0.02$ & $0.35 \pm 0.02$ & $0.48 \pm 0.02$ & 0.49 \\
\hline PSC III-3 & PBTFA11/PC ${ }_{61} \mathrm{BM}$ & $1: 3$ & $0.48 \pm 0.03$ & $2.68 \pm 0.01$ & $0.31 \pm 0.03$ & $0.40 \pm 0.03$ & 0.41 \\
\hline PSC IV & PBTFA13/PC 71 BM & $1: 3$ & $0.64 \pm 0.03$ & $8.65 \pm 0.02$ & $0.39 \pm 0.02$ & $2.17 \pm 0.03$ & 2.20 \\
\hline PSC V & PBTFA12/PC 71 BM & $1: 2$ & $0.61 \pm 0.02$ & $7.25 \pm 0.03$ & $0.40 \pm 0.01$ & $1.77 \pm 0.02$ & 1.79 \\
\hline PSC VI & PBTFA11/PC 71 BM & $1: 1$ & $0.59 \pm 0.02$ & $6.23 \pm 0.02$ & $0.38 \pm 0.02$ & $1.40 \pm 0.03$ & 1.43 \\
\hline
\end{tabular}

${ }^{*} \mathrm{PV}$ properties of illuminated (AM1.5 solar simulator, $100 \mathrm{~mW} \cdot \mathrm{cm}^{-2}$ ) PT/PC61BM and PT/PC ${ }_{71} \mathrm{BM}$-based PSCs. 
respectively. The optimal content of $\mathrm{PC}_{61} \mathrm{BM}$ seemed to be related to the content of electron-deficient DFBT units in the PT backbone. PBTFA11, which had a relatively high $\mathrm{DFBT}$ content, required a lower $\mathrm{PC}_{61} \mathrm{BM}$ content to achieve the best PV performance. In an attempt to further improve the PV performance of the PT-based PSCs, we introduced $\mathrm{PC}_{71} \mathrm{BM}$ as the electron acceptor in the photoactive layer of the PSCs. Figure $9 \mathrm{~b}$ presents the photocurrent density-

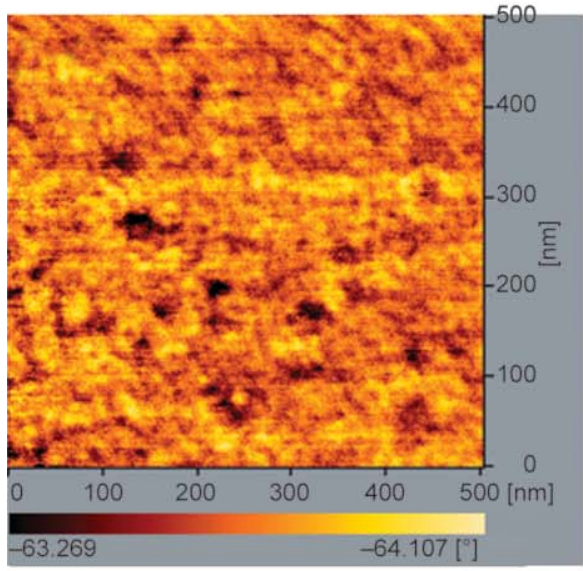
a)

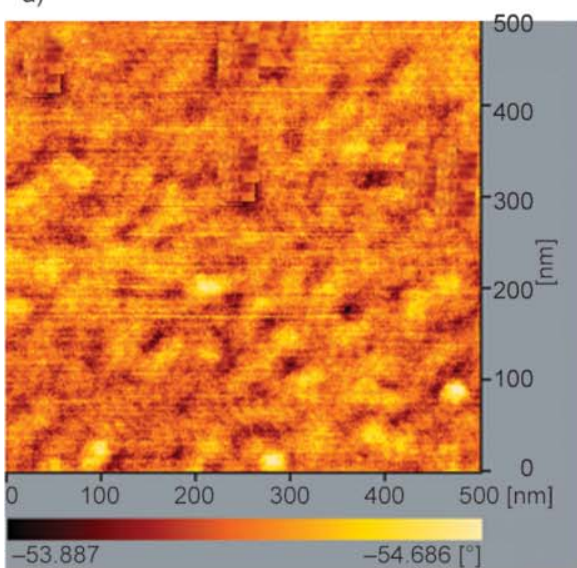
b)

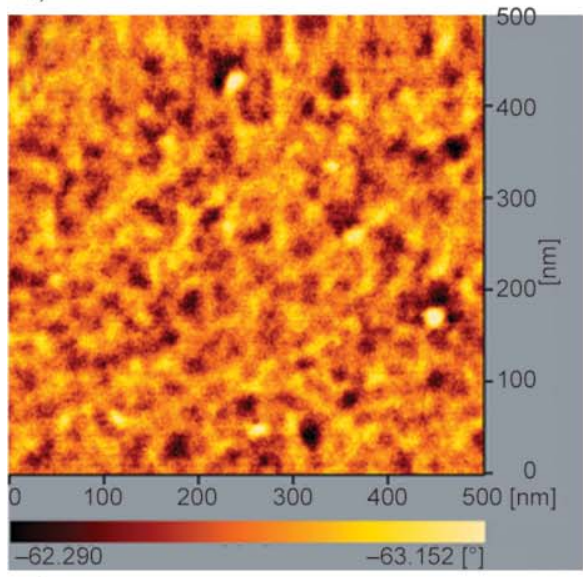

c) voltage plots of the PSCs incorporating PBTFA13/ $\mathrm{PC}_{71} \mathrm{BM}(\mathrm{w} / \mathrm{w}=1: 3)$, PBTFA12/PC $\mathrm{PC}_{71} \mathrm{BM}(\mathrm{w} / \mathrm{w}=$ $1: 2)$, and PBTFA11/PC $\mathrm{PC}_{71} \mathrm{BM}(\mathrm{w} / \mathrm{w}=1: 1)$ blends (PSC IV-PSC VI, respectively). Table 3 summarizes the PV properties of these PSCs. PV properties of the PSCs based on the PT/PC 71 BM blend films were superior to those of the PSCs based on the PT/ $\mathrm{PC}_{61} \mathrm{BM}$ blend films, because of the stronger and broader absorption of $\mathrm{PC}_{71} \mathrm{BM}$ in the visible region

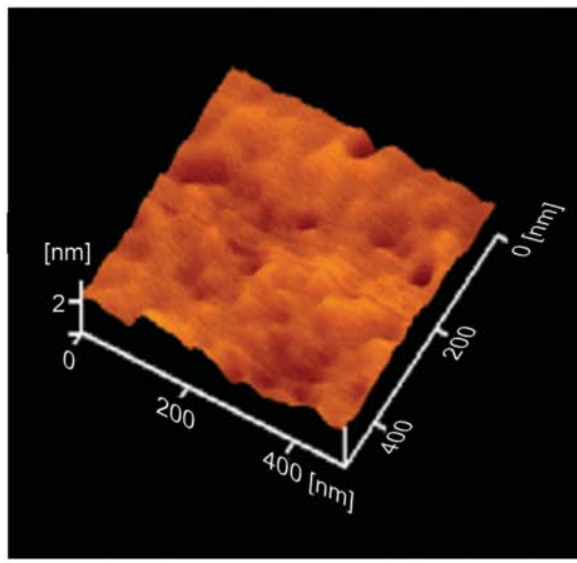

d)

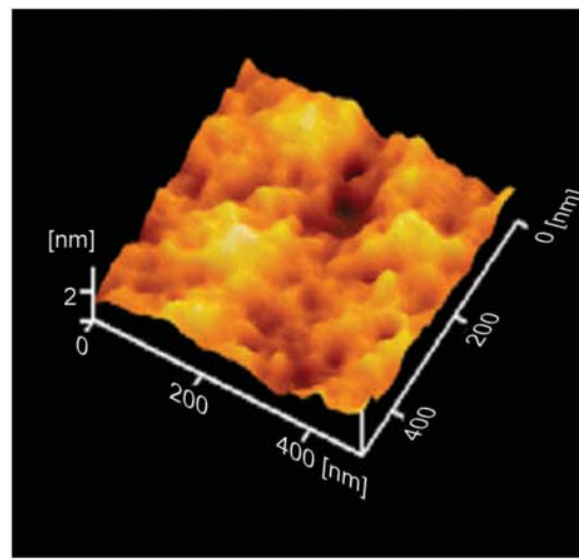

e)

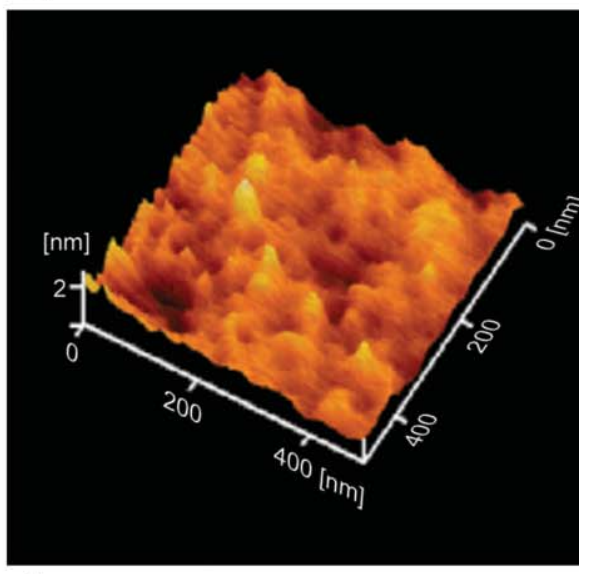

Figure 10. Tapping-mode AFM (a-c) topographic and $(\mathrm{d}-\mathrm{f})$ phase images of PT blend films [(a, d) PBTFA11/PC ${ }_{71} B M$ $(\mathrm{w} / \mathrm{w}=1: 1) ;(\mathrm{b}, \mathrm{e})$ PBTFA12/PC $71 \mathrm{BM}(\mathrm{w} / \mathrm{w}=1: 2) ;(\mathrm{c}, \mathrm{f})$ PBTFA13/PC $\left.\mathrm{P}_{71} \mathrm{BM}(\mathrm{w} / \mathrm{w}=1: 3)\right]$ that had been subjected to annealing at $110^{\circ} \mathrm{C}$ for $10 \mathrm{~min}$ 
[29]. Moreover, the values of $J_{\mathrm{SC}}$ and PCE of the PBTFA13/PC ${ }_{71}$ BM- and PBTFA12/PC 71 BM-based PSCs were higher than those of the PBTFA11/ $\mathrm{PC}_{71} \mathrm{BM}-$ blend PSCs. The AFM images in Figure 10 indicate that phase-separated interpenetrating networks with sizable domains were formed in the photoactive layers for the $\mathrm{PT} / \mathrm{PC}_{71} \mathrm{BM}$ blend films. Moreover, the phase separation for the PBTFA13/ $\mathrm{PC}_{71} \mathrm{BM}$ blend film was more obvious than that for the PBTFA12/PC 71 BM and PBTFA11/PC 71 BM blend

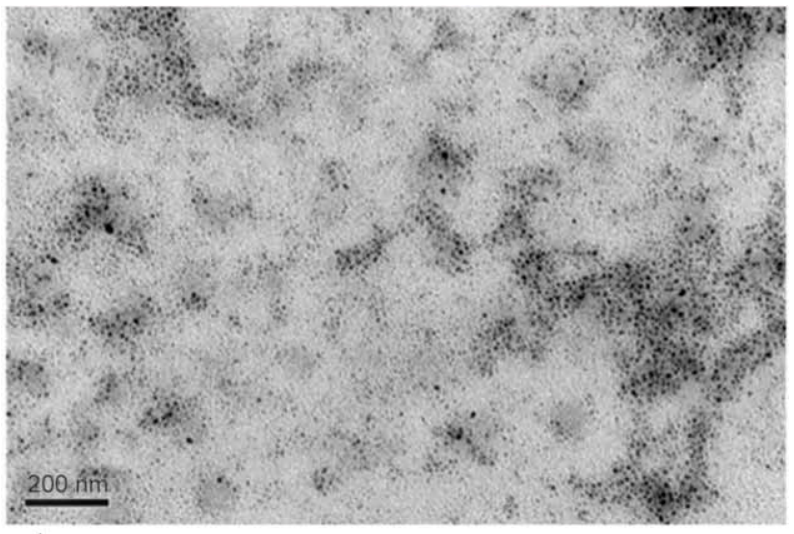

a)

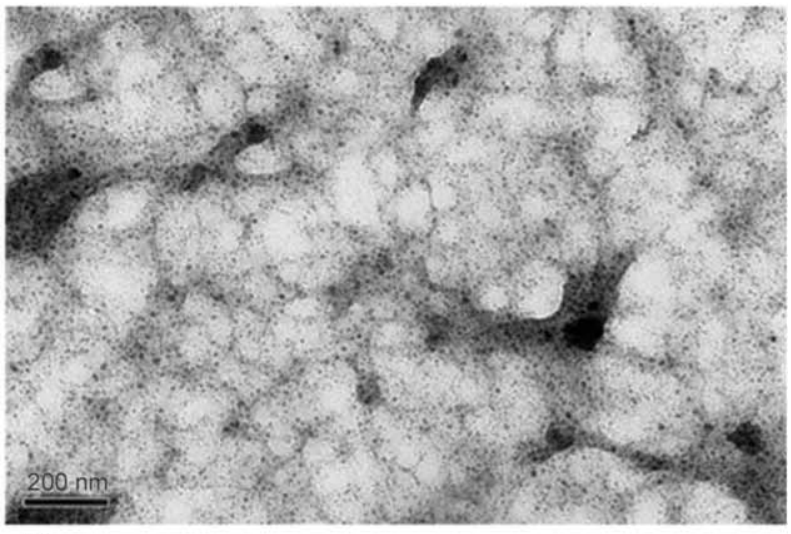

b)

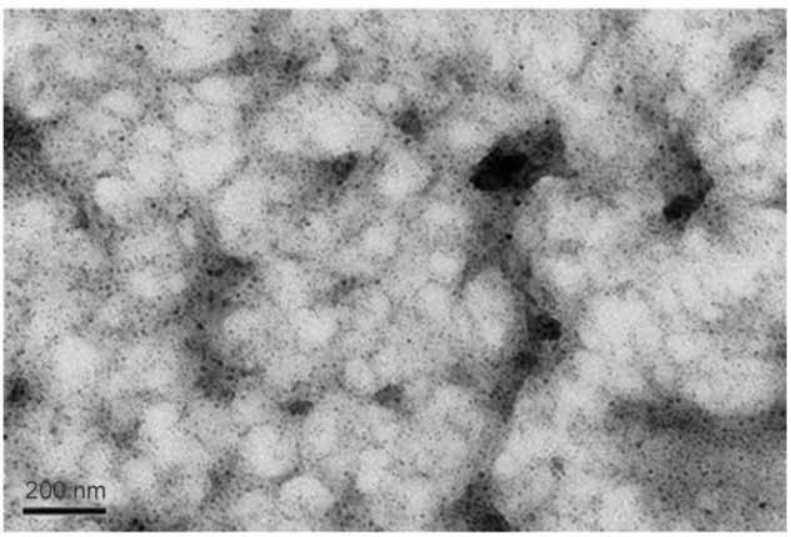

c)

Figure 11. TEM images of (a) PBTFA11/PC $71 \mathrm{BM}(\mathrm{w} / \mathrm{w}=$ 1:1), (b) PBTFA12/PC $\mathrm{PC}_{71} \mathrm{BM}(\mathrm{w} / \mathrm{w}=1: 2)$, and (c) PBTFA13/PC $\mathrm{PC}_{71} \mathrm{BM}(\mathrm{w} / \mathrm{w}=1: 3)$ blend films that had been subjected to annealing at $110^{\circ} \mathrm{C}$ for $10 \mathrm{~min}$ films. We recorded TEM images (Figure 11) to further characterize the distribution of $\mathrm{PC}_{71} \mathrm{BM}$ in the $\mathrm{PT} / \mathrm{PC}_{71} \mathrm{BM}$ films. The dark areas in the images represent $\mathrm{PC}_{71} \mathrm{BM}$ domains, because the electron-scattering density of $\mathrm{PC}_{71} \mathrm{BM}$ was greater than that of the conjugated polymers. The presence of phase-separated interpenetrating networks with sizable domains in the photoactive layer was confirmed for the PBTFA13/PC 71 BM and PBTFA12/PC ${ }_{71} \mathrm{BM}$ blend films. In contrast, the phase separation on the nanoscale was insignificant for the PBTFA11/PC 71 BM blend film, presumably because of the low content of $\mathrm{PC}_{71} \mathrm{BM}$. Apart from that, the external quantum efficiency (EQE) spectra of these $\mathrm{PT} / \mathrm{PC}_{71} \mathrm{BM}$ based PSCs recorded under monochromatic irradiation are shown in Figure 12. The partial photo-response at a wavelength near $350 \mathrm{~nm}$ was contributed by the absorption of $\mathrm{PC}_{71} \mathrm{BM}$ [22]. The maximal EQE value of PBTFA13 based PSC was higher than those of PBTFA11 and PBTFA12 based PSCs. As a result, the PV properties of the PSC featuring the PBTFA13/ $\mathrm{PC}_{71} \mathrm{BM}$ blend film were superior to those of the PSCs based on the PBTFA11/PC ${ }_{71}$ BM and PBTFA12/ $\mathrm{PC}_{71} \mathrm{BM}$ blend films.

\section{Conclusions}

We have synthesized three 2-D PTs (PBTFA13, PBTFA12, PBTFA11) featuring an electron-deficient DFBT derivative as the conjugated units in the polymer backbone and $t$ TPA-containing moieties as pendant units. The incorporation of these moieties enhanced the conjugation effect within the extended conjugated frameworks of the polymers. The light absorption ability of the PTs was dependent upon the molar ratio of the electron-donating $t$ TPA-based pendant units and the electron-withdrawing DFBT units

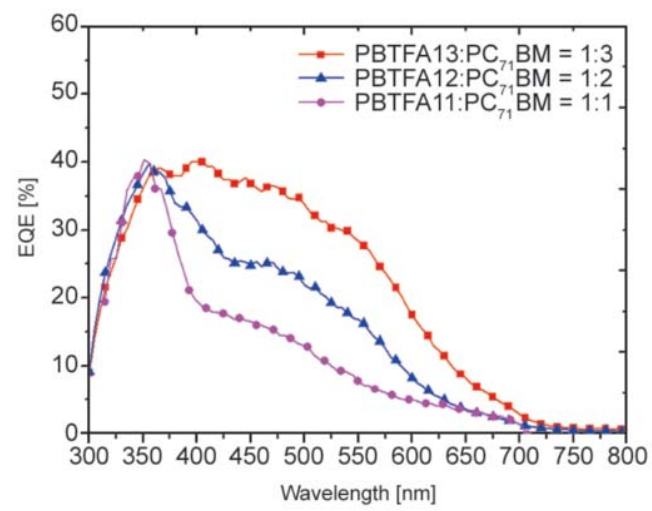

Figure 12. EQE spectra of $\mathrm{PT} / \mathrm{PC}_{71} \mathrm{BM}$-based solar cells under the best conditions 
in the polymer chains. The PV performance of the PBTFA13-based PSCs was superior to that of the PBTFA12- and PBTFA11-based PSCs.

\section{Acknowledgements}

We thank the Ministry of Science and Technology (MOST) of Taiwan for financial support (grant no 104-2221-E-005065-MY3).

\section{References}

[1] Liu F., Gu Y., Shen X., Ferdous S., Wang H-W., Russell T. P.: Characterization of the morphology of solutionprocessed bulk heterojunction organic photovoltaics. Progress in Polymer Science, 38, 1990-2052 (2013). https://doi.org/10.1016/j.progpolymsci.2013.07.010

[2] Orgiu E., Crivillers N., Rotzler J., Mayor M., Samori P.: Tuning the charge injection of P3HT-based organic thin-film transistors through electrode functionalization with oligophenylene SAMs. Journal of Materials Chemistry, 20, 10798-10800 (2015). https://doi.org/10.1039/c0jm03363d

[3] Lee R-H., Liu L-W.: Electroluminescence and photovoltaic properties of light-emitting devices and solar cells comprising 2-pyran-4-ylidene-malononitrile conjugated polymers. Dyes and Pigments, 84, 190-202 (2010). https://doi.org/10.1016/j.dyepig.2009.08.002

[4] Chen J-D., Cui C., Li Y-Q., Zhou L., Qu Q-D., Li C., Li Y., Tang J-X.: Single-junction polymer solar cells exceeding 10\% power conversion efficiency. Advanced Materials, 27, 1035-1041 (2015). https://doi.org/10.1002/adma.201404535

[5] Chen Y-H., Lin Y-Y., Chen Y-C., Lin J. T., Lee R-H., Kuo W-J., Jeng R-J.: Carbazole/fluorene copolymers with dimesitylboron pendants for blue light-emitting diodes. Polymer, 52, 976-986 (2011). https://doi.org/10.1016/j.polymer.2010.12.060

[6] An Q., Zhang F., Sun Q., Zhang M., Zhang J., Tang W., Yin X., Deng Z.: Efficient organic ternary solar cells with the third component as energy acceptor. Nano Energy, 26, 180-191 (2016). https://doi.org/10.1016/j.nanoen.2016.05.018

[7] An Q., Zhang F., Zhang J., Tang W., Deng Z., Hu B.: Versatile ternary organic solar cells: A critical review. Energy \& Environmental Science, 9, 281-322 (2016). https://doi.org/10.1039/c5ee02641e

[8] Su Y-W., Lan S-C., Wei K-H.: Organic photovoltaics. Materials Today, 15, 554-562 (2012). https://doi.org/10.1016/S1369-7021(13)70013-0

[9] Chen M-H., Hou J., Hong Z., Yang G., Sista S., Chen L-M., Yang Y.: Efficient polymer solar cells with thin active layers based on alternating polyfluorene copolymer/fullerene bulk heterojunctions. Advanced Materials, 21, 4238-4242 (2009).

https://doi.org/10.1002/adma.200900510
[10] Xu B., Zheng Z., Zhao K. Hou J.: A bifunctional interlayer material for modifying both the anode and cathode in highly efficient polymer solar cells. Advanced Materials, 28, 434-439 (2016). https://doi.org/10.1002/adma.201502989

[11] Casey A., Ashraf R. S., Fei Z., Heeney M.: Thioalkylsubstituted benzothiadiazole acceptors: Copolymerization with carbazole affords polymers with large stokes shifts and high solar cell voltages. Macromolecules, 47, 2279-2288 (2014). https://doi.org/10.1021/ma5000943

[12] Yao J., Yu C., Liu Z., Luo H., Yang Y., Zhang G., Zhang D.: Significant improvement of semiconducting performance of the diketopyrrolopyrrole-quaterthiophene conjugated polymer through side-chain engineering via hydrogen-bonding. Journal of the American Chemical Society, 138, 173-185 (2016). https://doi.org/10.1021/jacs.5b09737

[13] Jwo P-C., Lai Y-Y., Tsai C-E., Lai Y-Y., Liang W-W., Hsu C-S., Cheng Y-J.: A new ladder-type germaniumbridged dithienocarbazole arene and its donor-acceptor conjugated copolymers: Synthesis, molecular properties, and photovoltaic applications. Macromolecules, 47, 7386-7396 (2014). https://doi.org/10.1021/ma5018499

[14] Kim J. H., Park J. B., Shin S. A., Hyun M. H., Hwang D. H.: Low-bandgap copolymers consisting of 2,1,3benzoselenadiazole and carbazole derivatives with thiophene or selenophene $\pi$-bridges. Polymer, 55, 36053613 (2014). https://doi.org/10.1016/j.polymer.2014.05.055

[15] Subramaniyan S., Xin H., Kim F. S., Murari N. M., Courtright B. A. E., Jenekhe S. A.: Thiazolothiazole donor-acceptor conjugated polymer semiconductors for photovoltaic applications. Macromolecules, 47, 41994209 (2014).

https://doi.org/10.1021/ma500250j

[16] Duan C., Chen K-S., Huang F., Yip H-L., Liu S., Zhang J., Jen A. K-Y., Cao Y.: Synthesis, characterization, and photovoltaic properties of carbazole-based two-dimensional conjugated polymers with donor- $\pi$-bridge-acceptor side chains. Chemistry of Materials, 22, 6444-6452 (2010). https://doi.org/10.1021/cm1027157

[17] Li Y., Xue L., Xia H., Xu B., Wen S. Tian W.: Synthesis and properties of polythiophene derivatives containing triphenylamine moiety and their photovoltaic applications. Journal of Polymer Science Part A: Polymer Chemistry, 46, 3970-3984 (2008). https://doi.org/10.1002/pola.22737

[18] Chang Y-T., Hsu S-L., Su M-H., Wei K-H.: Intramolecular donor-acceptor regioregular poly(hexylphenanthrenyl-imidazole thiophene) exhibits enhanced hole mobility for heterojunction solar cell applications. Advanced Materials, 21, 2093-2097 (2009). https://doi.org/10.1002/adma.200802379 
[19] Zhang Z-G., Zhang S., Min J., Chui C., Zhang J., Zhang M., Li Y.: Conjugated side-chain isolated polythiophene: Synthesis and photovoltaic application. Macromolecules, 45, 113-118 (2012).

https://doi.org/10.1021/ma201718x

[20] Tsai J-H., Lee W-Y., Chen W-C., Yu C-Y., Hwang GW., Ting C.: New two-dimensional thiophene-acceptor conjugated copolymers for field effect transistor and photovoltaic cell applications. Chemistry of Materials, 22, 3290-3299 (2010).

https://doi.org/10.1021/cm100661z

[21] Gu Z., Shen P., Tsang S-W., Tao Y., Zhao B., Tang P., Nie Y., Fang Y., Tan S.: Development of a new benzo (1,2-b:4,5-b')dithiophene-based copolymer with conjugated dithienylbenzothiadiazole-vinylene side chains for efficient solar cells. Chemical Communications, 47, 9381-9383 (2011).

https://doi.org/10.1039/c1cc12851e

[22] Wang H-J., Chan L-H., Chen C-P., Lin S-L., Lee R-H., Jeng R-J.: Bulky side-chain density effect on the photophysical, electrochemical and photovoltaic properties of polythiophene derivatives. Polymer, 52, 326-338 (2011).

https://doi.org/10.1016/j.polymer.2010.11.036

[23] Chakravarthi N., Gunasekar K., Kim C. S., Kim D. H., Song M., Park Y. G., Lee J. Y., Shin Y., Kang I-N., Jin S-H.: Synthesis, characterization, and photovoltaic properties of 4,8-dithienylbenzo[1,2-b:4,5-b']dithiophene-based donor-acceptor polymers with new polymerization and 2D conjugation extension pathways: A potential donor building block for high performance and stable inverted organic solar cells. Macromolecules, 48, 2454-2465 (2015).

https://doi.org/10.1021/acs.macromol.5b00115

[24] Mei S., Wu F., Huang Y., Zhao B., Tan S.: Synthesis and photovoltaic properties of the copolymers based on 3 -ethylrhodanine side group. European Polymer Journal, 67, 31-39 (2015).

https://doi.org/10.1016/j.eurpolymj.2015.03.049

[25] Morvillo P., Diana R., Fontanesi C., Ricciardi R., Lanzi M., Mucci A., Tassinari F., Schenetti L., Minarini C., Parenti F.: Low band gap polymers for application in solar cells: Synthesis and characterization of thienothiophene-thiophene copolymers. Polymer Chemistry, 5, 2391-2400 (2014).

https://doi.org/10.1039/C3PY01618H

[26] Huo L., Liu T., Fan B., Zhao Z., Sun X., Wei D., Yu M., Liu Y., Sun Y.: Organic solar cells based on a $2 \mathrm{D}$ benzo [1,2-b:4,5-b']difuran-conjugated polymer with highpower conversion efficiency. Advanced Materials, 27, 6969-6975 (2015).

https://doi.org/10.1002/adma.201503023

[27] Ye L., Zhang S., Zhao W., Yao H., Hou J.: Highly efficient 2D-conjugated benzodithiophene-based photovoltaic polymer with linear alkylthio side chain. Chemistry of Materials, 26, 3603-3605 (2014).

https://doi.org/10.1021/cm501513n
[28] Zhang S., Ye L., Zhao W., Liu D., Yao H., Hou J.: Side chain selection for designing highly efficient photovoltaic polymers with 2D-conjugated structure. Macromolecules, 47, 4653-4659 (2014).

https://doi.org/10.1021/ma500829r

[29] Wang H-J., Tzeng J-Y., Chou C-W., Huang C-Y., Lee R-H., Jeng R-J.: Novel polythiophene derivatives functionalized with conjugated side-chain pendants comprising triphenylamine/carbazole moieties for photovoltaic cell applications. Polymer Chemistry, 4, 506519 (2013).

https://doi.org/10.1039/C2PY20477K

[30] Fan Q., Liu Y., Yang P., Su W., Xiao M., Chen J., Li M., Wang X., Wang Y., Tan H., Yang R., Zhu W.: Benzodithiophene-based two-dimensional polymers with extended conjugated thienyltriphenylamine substituents for high-efficiency polymer solar cells. Organic Electronics, 23, 124-132 (2015).

https://doi.org/10.1016/j.orgel.2015.04.013

[31] Jiang J-M., Raghunath P., Lin H-K., Lin Y-C., Lin M. C., Wei K-H.: Location and number of selenium atoms in two-dimensional conjugated polymers affect their band-gap energies and photovoltaic performance. Macromolecules, 47, 7070-7080 (2014).

https://doi.org/10.1021/ma501720k

[32] Zhou P., Dang D., Fan J., Xiong W., Yang C., Tan H., Wang Y., Liu Y., Zhu W.: Increasing thiophene spacers between thieno[3,2-b]thiophene and benzothiadiazole units in backbone to enhance photovoltaic performance for their 2-D polymers. Dyes and Pigments, 112, 99104 (2015).

https://doi.org/10.1016/j.dyepig.2014.06.015

[33] Mühlbacher D., Scharber M., Morana M., Zhu Z., Waller D., Gaudiana R., Brabec C.: High photovoltaic performance of a low-bandgap polymer. Advanced Materials, 18, 2884-2889 (2006).

https://doi.org/10.1002/adma.200600160

[34] Hou J., Chen H-Y., Zhang S., Li G., Yang Y.: Synthesis, characterization, and photovoltaic properties of a low band gap polymer based on silole-containing polythiophenes and 2,1,3-benzothiadiazole. Journal of the American Chemical Society, 130, 16144-16145 (2008).

https://doi.org/10.1021/ja806687u

[35] You J., Dou L., Yoshimura K., Kato T., Ohya K., Moriarty T., Emery K., Chen C-C., Gao J., Li G., Yang Y.: A polymer tandem solar cell with $10.6 \%$ power conversion efficiency. Nature Communications, 2013, 1-10 (2013). https://doi.org/10.1038/ncomms2411

[36] Li G., Kang C., Gong X., Zhang J., Li W., Li C., Dong H., Hu W., Bo Z.: 5,6-difluorobenzothiadiazole and silafluorene based conjugated polymers for organic photovoltaic cells. Journal of Materials Chemistry C, 2, 51165123 (2014).

https://doi.org/10.1039/C4TC00340C 
[37] Deng P., Wu B., Lei Y., Cao H., Ong B. S.: Regioregular and random difluorobenzothiadiazole electron donoracceptor polymer semiconductors for thin-film transistors and polymer solar cells. Macromolecules, 49, 25412548 (2016).

https://doi.org/10.1021/acs.macromol.5b02754

[38] Li Z., Lu J., Tse S-C., Zhou J., Du X., Tao Y., Ding J.: Synthesis and applications of difluorobenzothiadiazole based conjugated polymers for organic photovoltaics. Journal of Materials Chemistry, 21, 3226-3233 (2011). https://doi.org/10.1039/C0JM04166A

[39] Yuan L., Zhao Y., Zhang J., Zhang Y., Zhu L., Lu K., Yan W., Wei Z.: Oligomeric donor material for high-efficiency organic solar cells: Breaking down a polymer. Advanced Materials, 27, 4229-4233 (2015).

https://doi.org/10.1002/adma.201501491

[40] Wang J., Xiao M., Chen W., Qiu M., Du Z., Zhu W., Wen S., Wang N., Yang R.: Extending $\pi$-conjugation system with benzene: An effective method to improve the properties of benzodithiophene-based polymer for highly efficient organic solar cells. Macromolecules, 47, 7823 7830 (2014).

https://doi.org/10.1021/ma501756p

[41] Wang J-L., Xiao F., Yan J., Wu Z., Liu K-K., Chang Z-F., Zhang R-B., Chen H., Wu H-B., Cao Y.: Difluorobenzothiadiazole-based small-molecule organic solar cells with $8.7 \%$ efficiency by tuning of $\pi$-conjugated spacers and solvent vapor annealing. Advanced Functional Materials, 26, 1803-1812 (2016).

https://doi.org/10.1002/adfm.201505020

[42] Dou L. T., Chen C-C., Yoshimura K., Ohya K., Chang W-H., Gao J., Liu Y. S., Richard E., Yang Y.: Synthesis of 5H-dithieno[3,2-b:2',3'-d]pyran as an electron-rich building block for donor-acceptor type low-bandgap polymers. Macromolecules, 46, 3384-3390 (2013). https://doi.org/10.1021/ma400452j

[43] Hou J., Tan Z., Yan Y., He Y., Yang C., Li Y.: Synthesis and photovoltaic properties of two-dimensional conjugated polythiophenes with bi(thienylenevinylene) side chains. Journal of the American Chemical Society, 128, 4911-4916 (2006). https://doi.org/10.1021/ja060141m

[44] Hou J., Huo L., He C., Yang C., Li Y.: Synthesis and absorption spectra of poly(3-(phenylenevinyl)thiophene)s with conjugated side chains. Macromolecules, 39, 594 603 (2006).

https://doi.org/10.1021/ma051883n

[45] Sang G., Zhou E., Huang Y., Zou Y., Zhao G., Li Y.: Incorporation of thienylenevinylene and triphenylamine moieties into polythiophene side chains for all-polymer photovoltaic applications. The Journal of Physical Chemistry C, 113, 5879-5885 (2009).

https://doi.org/10.1021/jp9000048

[46] Li W., Han Y., Chen Y., Li C., Li B., Bo Z.: Polythiophenes with carbazole side chains: Design, synthesis and their application in organic solar cells. Macromolecular Chemistry and Physics, 211, 948-955 (2010).

https://doi.org/10.1002/macp.200900641
[47] Wang H-J., Chan L-H., Chen C-P., Lee R-H., Su W-C., Jeng R-J.: Polythiophene derivative comprising carbazoles as pendant groups for polymer solar cell applications. Thin Solid Films, 519, 5264-5269 (2011). https://doi.org/10.1016/j.tsf.2011.01.173

[48] Zhang G., Fu Y., Xie Z., Zhang Q.: Synthesis of low bandgap polymer based on 3,6-dithien-2-yl-2,5-dialkylpyrrolo[3,4-c]pyrrole-1,4-dione for photovoltaic applications. Solar Energy Materials and Solar Cells, 95, 1168-1173 (2011).

https://doi.org/10.1016/j.solmat.2010.12.049

[50] Shiau S-Y., Chang C-H., Chen W-J., Wang H-J., Jeng R-J., Lee R-H.: Star-shaped organic semiconductors with planar triazine core and diketopyrrolopyrrole branches for solution-processed small-molecule organic solar cells. Dyes and Pigments, 115, 35-49 (2015).

https://doi.org/10.1016/j.dyepig.2014.12.007

[50] Zou Y., Gendron D., Negau-Plesu R., Leclerc M.: Synthesis and characterization of new low-bandgap diketopyrrolopyrrole-based copolymers. Macromolecules, 42, 6361-6365 (2009). https://doi.org/10.1021/ma901114j

[51] Lanzi M., Bertinelli F., Costa-Bizzarri P., Paganin L., Cesari G.: Tuning of the electronic properties of selfassembling and highly sensitive chromic polyalkylthiophenes. European Polymer Journal, 43, 835-846 (2007). https://doi.org/10.1016/j.eurpolymj.2006.12.025

[52] Zhang M., Zhang F., An Q., Sun Q., Wang W., Zhang J., Tang W.: Highly efficient ternary polymer solar cells by optimizing photon harvesting and charge carrier transport. Nano Energy, 22, 241-254 (2016). https://doi.org/10.1016/j.nanoen.2016.02.032

[53] Sun Q., Zhang F., Wang J., An Q., Zhao C., Li L., Teng F., Hu B.: A two-step strategy to clarify the roles of a solution processed PFN interfacial layer in highly efficient polymer solar cells. Journal of Materials Chemistry A, 3, 18432-18441 (2015). https://doi.org/10.1039/C5TA05117G

[54] Ma X., Zhang F., An Q., Sun Q., Zhang M., Zhang J.: Dramatically boosted efficiency of small molecule solar cells by synergistically optimizing molecular aggregation and crystallinity. ACS Sustainable Chemistry and Engineering, 5, 1982-1989 (2017).

https://doi.org/10.1021/acssuschemeng.6b02808

[55] Lee R-H., Huang J-L., Chi C-H.: Conjugated polymerfunctionalized graphite oxide sheets thin films for enhanced photovoltaic properties of polymer solar cells. Journal of Polymer Science Part B: Polymer Physics, 51, 137-148 (2013). https://doi.org/10.1002/polb.23180

[56] Chaudhary S., Lu H., Müller A. M., Bardeen C. J., Ozkan M.: Hierarchical placement and associated optoelectronic impact of carbon nanotubes in polymerfullerene solar cells. Nano Letters, 7, 1973-1979 (2007). https://doi.org/10.1021/n10707171 